\title{
Does Patient's Initial Evaluation Predict a Change in Optimal Pressure on CPAP Retitration?*
}

\author{
Narayan P. Verma \\ OUWB School of Medicine and B. G. Tricounty Neurology and Sleep Clinic, Warren, MI, USA. \\ Email: narayangod@aol.com
}

Received December $18^{\text {th }}$, 2013; revised January $20^{\text {th }}$, 2014; accepted February $10^{\text {th }}, 2014$

Copyright (C) 2014 Narayan P. Verma. This is an open access article distributed under the Creative Commons Attribution License, which permits unrestricted use, distribution, and reproduction in any medium, provided the original work is properly cited. In accordance of the Creative Commons Attribution License all Copyrights (c) 2014 are reserved for SCIRP and the owner of the intellectual property Narayan P. Verma. All Copyright (C) 2014 are guarded by law and by SCIRP as a guardian.

\section{ABSTRACT}

Introduction: Only vindication of a nasal continuous positive airway pressure (CPAP) retitration procedure will be an actual change in the optimal CPAP pressure after that test. The purpose of this study was to identify any items in patient characteristics, clinical features, baseline PSG and initial CPAP titration as predictors of change in optimal pressure on CPAP retitration. Methods: 46 patients with obstructive sleep apnea (OSA) were divided in two groups: Group I (optimal pressure was changed on CPAP retitration): $\mathbf{N}=30$, M 22 and F 8, age 31 - 72, BMI 26 - $50 \mathrm{Kg} / \mathrm{m}^{2}$, neck size 15 - 20", tonsillectomy in 8, narrow oropharynx in 15, uvuvlopalatopharyngoplasty (UP3) in 2, abnormal chin in 3, deviated nasal septum (DNS) and prior nose surgery in 1 each, initial CPAP pressure 6 - $19 \mathrm{~cm}$, sleep efficiency 65\% - 98\%, REM latency 0 - 304 minutes and residual apnea hypopnea index (AHI) 0 - 23/hour. Group II (optimal pressure unchanged after CPAP retitration): N = 16, M 11 and 5 F, age 32 69, BMI 23 - $62 \mathrm{Kg} / \mathrm{m}^{2}$, neck size 14.5 - 20", tonsillectomy in 6, narrow oropharynx in 5, abnormal chin in 4, corrective nasal surgery in 2, DNS in 1, initial CPAP pressure 8 - $13 \mathrm{~cm}$ of H2O, sleep efficiency 69\% - 95\%, REM latency 0 - 270 minutes and residual AHI 0 - 19/hour. The statistical analyses were performed using two-tailed Fisher's $t$ test and unpaired $t$ test. A p value of $<\mathbf{0 . 0 5}$ was considered statistically significant. Results: Patient characteristics (age, gender, neck size, and BMI), clinical features (tonsillar status, oropharyngeal narrowing, chin abnormality, DNS/nasal surgery or UP3), baseline PSG or initial CPAP titration (sleep efficiency, REM latency, residual AHI and initial CPAP pressure) did not differ significantly between the 2 groups $(p=0.09-0.99)$. Conclusion: Patient characteristics, clinical features or variables on baseline PSG and initial CPAP titration do not predict a change in optimal pressure on CPAP retitration. The results suggest that 1) Significant weight change; 2) Patient's subjective feeling of pressure being too high or insufficient; 3 ) Residual or recurrent daytime sleepiness uncorrected by interface readjustments; 4) Post-operative evaluation after palliative UP3 Maxillomandibular advancement or tonsillectomy and adenoidectomy; and 5) Annual retitrations in high risk occupations (e.g. truck driver or pilot) are the best current, empiric and clinical guidelines for CPAP retitration.

\section{KEYWORDS}

\section{Obstructive Sleep Apnea; CPAP Titration; CPAP Retitration}

\section{Introduction}

The prevalence of obstructive sleep apnea (OSA) has been estimated to be $1 \%-3 \%, 2 \%$ and $4 \%$ in children, middle aged women and men respectively [1-3]. The

*Abstract published in SLEEP, Volume 30, Abstract supplement, 2007; A179.

Presented at the 21st Annual Meeting of the Associated Professional Sleep Societies (APSS) 2007. most reliably effective treatment for OSA is continuous positive airway pressure (CPAP) [4-6]. It is believed to prevent upper airway collapse during sleep by acting like a pneumatic splint $[7,8]$. A CPAP titration's objective is to identify an optimal positive airway pressure which is able to overcome airflow limitation in all sleep stages and body positions thereby preventing apneic/hypopneic events, snoring and respiratory effort related arousals, 
correct desaturations and improve sleep architecture.

However, the optimal CPAP is dynamic and is expected to vary over a period of time due to variety of reasons including but not limited to changes in upper airway e.g. adeno-tonsillar hypertrophy ; palliative and therapeutic interventions like adeno-tonsillectomy [9], UP3 [10], nasal surgery, mandibular advancement devices, tracheostomy and bariatric surgery [11]; craniofacial and pharangeal development in children; upper airway infection/obstruction/pathology such as rhinitis, nasal polyps or deviated nasal septum [12]; change in sleeping position; fluctuation in body mass index (BMI) and changes in lung volume [13].

Therefore, a re-evaluation of CPAP optimal pressure may be needed to change the initial pressure for effective OSA treatment. A retitration study is done annually as that is a frequency approved by most insurances or guided by the changes in objective/subjective measures of sleep and daytime somnolence on clinical follow up visits. The criteria for CPAP retitration are not clearly defined and the optimum pressure is not always different on reevaluation and in a number of OSA patients, it remains unchanged. This retrospective study was therefore designed to identify any characteristics present on initial clinic visit, baseline PSG and initial CPAP titration which might indicate/predict a change in optimal pressure on CPAP retitration.

\section{Methods}

\subsection{Subjects}

We studied forty six patients with OSA who presented at our sleep lab for CPAP retitration. The patients were evaluated by a board-certified neurologist who is also a board-certified sleep specialist, in a nationally accredited sleep center by a detailed medical history supplemented with standard sleep-wake questionnaire, neurological examination and examination relevant to sleep disorder evaluation such as neck size, chin size and position, jaw alignment, oropharyngeal examination. The patients were divided into two groups according to whether CPAP pressure on retitration study changed (Group I) or remained unchanged (Group II).

Thirty patients were in Group I (22 males and 8 females, age range 31 - 72 years, BMI range $26-50 \mathrm{Kg} / \mathrm{m}^{2}$, neck size range 15 - 20", 8 patients with tonsillectomy, narrow oropharynx in 15 patients, 2 patients with UP3, abnormal chin in 3 patients, deviated nasal septum (DNS) and prior nose surgery in one patient each, initial CPAP pressure range 6 - $19 \mathrm{~cm}$ of H2O, sleep efficiency range 65\% - 98\%, REM latency range 0 - 304 minutes and residual AHI range 0 - 23/hour).

Sixteen patients were in Group II (11 males and 5 females, age range 32 - $69 \mathrm{yr}$, BMI range 23 - $62 \mathrm{Kg} / \mathrm{m}^{2}$, neck size range 14.5 - 20", 6 patients with tonsillectomy, 5 patients with narrow oropharynx , abnormal chin in 4 patients, corrective nasal surgery in 2 patients, DNS in 1 patient, initial CPAP pressure range $8-13 \mathrm{~cm}$ of $\mathrm{H} 2 \mathrm{O}$, sleep efficiency range 69\% - 95\%, REM latency range 0 270 minutes and residual AHI range 0 - 19/hour.) Both groups were matched for age, gender, neck size, BMI, tonsillar status, oropharangeal narrowing, chin abnormality and upper airway surgery.

\subsection{PSG}

Single overnight PSGs were performed on forty six patients utilizing the AASM guidelines [14] prior to those most recently updated in 2005. The older data were analysed as currently it is hard to accumulate enough patients due to restrictions placed on CPAP retitrations by insurance companies. A 12 channel montage was utilized recording EEG, EOG, EKG, submental and tibial EMG, naso-oral airflow, thoracic and abdominal effort and $\mathrm{O} 2$ saturation by pulse oximeter. Sandman Elite hardware and software was utilized. The patients were evaluated in an accredited sleep laboratory in sound attenuated rooms, monitored by an infra-red camera. The records were scored by Rechtkaffen and Kale's method which was the prevalent method of scoring at that time [15] except for combining stages 3 and 4 as delta sleep and scoring movement time as arousal (2 - $15 \mathrm{sec}$ ) or awakenings (>15 sec) depending on duration. Various indices of sleep architecture analyzed were sleep efficiency, number of awakenings, number of stage shifts, percentage of various stages of sleep, sleep latency (i.e. latency to 3 consecutive epochs of stage 1 or first epoch of stage 2, REM or delta sleep), wake after sleep onset, latency to first REM period and apnea-hypopnea index (AHI). Apneas and hypopneas were scored according to guidelines prevalent at that time and are reproduced in Table 1.

\subsection{CPAP-Titration and Retitration Studies}

The polysomnograms performed with CPAP measured the same parameters as the baseline study. The range of pressure of the CPAP was set from 4 to $20 \mathrm{~cm}$ of $\mathrm{H} 2 \mathrm{O}$. During retitration studies the CPAP pressure was usually started several $\mathrm{cm}$ of water below the prescribed level and was gradually increased until the optimal pressure was found. Optimal pressure was defined as one which eliminated apneas, hypopneas, respiratory arousals, UARS, snoring and O2 desaturations in both supine position and REM sleep while improving sleep efficiency and decreasing sleep disruption as measured by improved stage 1 percentage and decreased stage-shifts. The study was not controlled for the sleep technologist but in general our sleep laboratory staff has a very low turnover rate. 


\subsection{Statistical Analysis}

The statistical analyses were performed using two-tailed Fisher's exact test or one tailed unpaired $t$ test. A p value of $<0.05$ was considered statistically significant.

\section{Results}

The results of this study failed to identify any items in patient characteristics, clinical features, initial PSG and initial CPAP titration as predictors of change in optimal pressure on CPAP retitration. There was no significant difference between age, gender, neck size, BMI, tonsillar status, oropharangeal narrowing, chin abnormality, upper airway surgery, sleep efficiency, REM latency, degree of sleep disruption, baseline AHI, residual AHI and initial $\mathrm{CPAP}$ pressure in Group I and Group II patients ( $\mathrm{p}$ value = $0.09-0.99$ ).

The results are summarized in Table 2.

Table 1. Scoring criteria for respiratory events.

\begin{tabular}{|c|c|c|c|c|}
\hline Respiratory event & Airflow reduction & Respiratory effort & O2 Desaturation & Duration \\
\hline Obstructive apnea & $>90 \%$ & Continued/Increased & - & 10 sec or more \\
\hline \multirow[t]{2}{*}{ Hypopnea } & $>50 \% \&<90 \%$ & NA & - & 10 sec or more \\
\hline & $>30 \% \&<50 \%$ & NA & $\begin{array}{l}3 \% \text { or more and/or terminated } \\
\text { by a respiratory arousal }\end{array}$ & 10 sec or more \\
\hline Central apnea & $>90 \%$ & Reduced $>90 \%$ & - & 10 sec or more \\
\hline Mixed apnea & $>90 \%$ & $\begin{array}{c}\text { Reduced more than } 90 \% \text { for at least } 5 \\
\text { seconds prior to continued or increased } \\
\text { effort }\end{array}$ & - & 10 sec or more \\
\hline
\end{tabular}

Table 2. Statistical difference between the study groups $(\mathrm{df}=\mathbf{4 4})$.

\begin{tabular}{|c|c|c|c|c|}
\hline & t value & Standard error of difference & Two-tailed “p value” & 95\% Confidence interval \\
\hline \multicolumn{5}{|l|}{ Patient characteristics } \\
\hline Age & 0.4966 & 3.692 & 0.6219 & -9.2739 to 5.6071 \\
\hline Gender ${ }^{*}$ & - & - & 0.7441 & - \\
\hline Neck size & 0.0000 & 0.310 & 1.0000 & -0.6200 to 0.6200 \\
\hline BMI & 0.4846 & 2.136 & 0.6303 & -5.3391 to 3.2691 \\
\hline \multicolumn{5}{|l|}{ Clinical characteristics } \\
\hline Tonsillar status* $^{*}$ & - & - & 0.5115 & - \\
\hline Oropharangeal status ${ }^{*}$ & - & - & 0.3496 & - \\
\hline Chin morphology ${ }^{*}$ & - & - & 0.2163 & - \\
\hline Nasal morphology ${ }^{*}$ & - & - & 0.3247 & - \\
\hline \multicolumn{5}{|l|}{ Baseline PSG parameters } \\
\hline Sleep efficiency & 1.2477 & 3.241 & 0.2192 & -2.5011 to 10.5875 \\
\hline Wake before sleep & 0.4579 & 6.240 & 0.6494 & -15.4587 to 9.7439 \\
\hline Wake during sleep & 1.7103 & 12.287 & 0.0948 & -21.0155 to 3.7992 \\
\hline Stage 1\% & 1.1202 & 4.177 & 0.2691 & -3.7561 to 13.1131 \\
\hline Stage $2 \%$ & 0.2764 & 3.849 & 0.7837 & -6.7086 to 8.8356 \\
\hline Delta \% & 1.3006 & 2.986 & 0.2007 & -9.9133 to 2.1467 \\
\hline REM \% & 1.1206 & 2.542 & 0.2690 & -7.9827 to 2.2851 \\
\hline REM latency & 0.9984 & 26.102 & 0.3239 & -26.6537 to 78.7745 \\
\hline AHI & 0.5090 & 9.510 & 0.6135 & -14.3645 to 24.0463 \\
\hline REM AHI & 0.9689 & 8.668 & 0.3383 & -9.1066 to 25.9025 \\
\hline Supine AHI & 0.3090 & 11.038 & 0.7589 & -25.7027 to 18.8814 \\
\hline $\mathrm{SaO} 2$ nadir & 0.3892 & 2.758 & 0.6992 & -4.4959 to 6.6422 \\
\hline \multicolumn{5}{|c|}{ Initial CPAP titration parameters } \\
\hline Sleep efficiency & 0.4582 & 4.064 & 0.6491 & -10.0535 to 6.3291 \\
\hline
\end{tabular}


Continued

\begin{tabular}{|c|c|c|c|c|}
\hline Wake before sleep & 0.3729 & 5.407 & 0.7110 & -8.8810 to 12.9142 \\
\hline Wake during sleep & 0.3257 & 11.795 & 0.7462 & -19.9303 to 27.6135 \\
\hline Stage $1 \%$ & 1.3746 & 3.114 & 0.1762 & -1.9956 to 10.5572 \\
\hline Stage $2 \%$ & 1.1570 & 3.548 & 0.2535 & -3.0457 to 11.2557 \\
\hline Delta \% & 1.7269 & 2.566 & 0.0912 & -9.6009 to 0.7401 \\
\hline REM \% & 1.7701 & 3.026 & 0.0836 & -11.4557 to 0.7423 \\
\hline REM latency & 0.3125 & 21.750 & 0.7562 & -50.6301 to 37.0383 \\
\hline Residual AHI & 0.7611 & 1.943 & 0.4507 & -5.3937 to 2.4367 \\
\hline Initial CPAP optimal pressure & 0.2277 & 0.896 & 0.8209 & -1.6021 to 2.0103 \\
\hline
\end{tabular}

*Fisher exact test.

\section{Discussion}

An identification of a predictor(s) for a change in optimal CPAP pressure on CPAP retitration would be an attractive solution to cut down health costs and reduce sleep laboratories backlog substantially by minimizing the number of unnecessary retitration studies. Also, recognition of patients who might need a different pressure may improve compliance and reduce the risks of OSA not optimally treated.

However, our study results failed to disclose any predictor(s) in patient characteristics, clinical features, baseline PSG or variables on initial CPAP titration.

The limitations of the study include limited number of subjects and inability to perform multivariate logistic regression analysis due to that reason. However, it is hard to find a large number of such patients in a given lab due to current climate of insurances severely restricting repeat titration studies.

Thus intuitive and empiric clinical criteria such as 1) body mass index fluctuation; 2) patient's subjective feeling of pressure being too high or insufficient; 3 ) subjective measures of non refreshing sleep and excessive daytime sleepiness despite interface readjustments; 4) postoperative evaluation after palliative UP3, bariatric surgery, tonsillectomy and adenoidectomy or MMA (Maxillo-mandibular Advancement) surgery; and 5) annual retitrations in high risk occupations (e.g. commercial truck drivers, heavy machinery operators or pilots) remain the best current clinical guidelines for CPAP retitration.

In this author's experience, there are some other variables which signal the need for retitration but are hard to evaluate in a scientific study. They include, 1) Inadequate first titration with not enough supine and REM sleep; 2) Patient's difficulty in adjusting to the CPAP machine during first 72 hours of use; 3) Unsatisfactory compliance summary results from the computer chips in the CPAP including excessive leaks and inadequately controlled AHI and hypoxia despite several interface readjustments; and 4) Climbing blood pressure, poorly controlled blood sugars in diabetics or interruption of patient's clinical course by a complication such as myocardial infarction, stroke.

\section{Conflict of Interests}

No conflict of interest is present.

\section{REFERENCES}

[1] N. J. Ali, D. J. Pitson and J. R. Strading, "Snoring, Sleep Disturbance and Behaviour in 4 to 5 Years Olds," Archives of Disease in Childhood, Vol. 68, No. 3, 1993, pp. 360-366. http://dx.doi.org/10.1136/adc.68.3.360

[2] T. Gislason and Benediktsdottir, "Snoring, Apneic Episodes and Nocturnal Hypoxemia among Children 6 Months to 6 Years Old,” Chest, Vol. 107, No. 4, 1995, pp. 963-966. http://dx.doi.org/10.1378/chest.107.4.963

[3] T. Young, M. Palta, J. Dempsey, J. Skatrud, S. Weber and S. Badr, "The Occurrence of Sleep-Disordered Breathing among Middle Aged Adults,” The New England Journal of Medicine, Vol. 328, No. 17, 1993, pp. 1230-1235. http://dx.doi.org/10.1056/NEJM199304293281704

[4] ATS Statement, "Indications and Standards of Use of Nasal Continuous Positive Airway Pressure (CPAP) in Sleep Apnea Syndromes,” American Journal of Respiratory and Critical Care Medicine, Vol. 150, No. 6, 1994, pp. $1738-1745$.

[5] D. I. Loube, P. C. Gay, K. P. Strohl, A. I. Pack, D. P. White and N. A. Collop, "Indications for Positive Airway Pressure Treatment for Adult Obstructive Sleep Apnea Patients: A Consensus Statement,” Chest, Vol. 115, No. 3, 1999, pp. 863-866. http://dx.doi.org/10.1378/chest.115.3.863

[6] P. Lloberes, S. Marti, G. Sampol, A. Roca, T. Sagales, X. Munoz and M. Ferrer, "Predictive Factors of Quality of Life Improvement and Continuous Positive Airway Pressure Use in Patients with Sleep Apnea-Hypopnea Syndrome: Study at 1 Year,” Chest, Vol. 126, No. 4, 2004, pp. 1241-1247. http://dx.doi.org/10.1378/chest.126.4.1241

[7] R. J. Schwab, A. I. Pack, K. B. Gupta, L. J. Metzger, E. Oh, J. E. Getsy, E. A. Hoffman and W. B. Gefter, "Upper Airway and Soft Tissue Structural Changes Induced by CPAP in Normal Subjects," American Journal of Respi- 
ratory and Critical Care Medicine, Vol. 154, No. 4, 1996, pp. 1106-1116.

http://dx.doi.org/10.1164/ajrccm.154.4.8887615

[8] N. C. Abbey, A. J. Block, D. Green, A. Mancuso and D. W. Hellard, "Measurement of Pharyngeal Volume by Digitized Magnetic Resonance Imaging: Effect of Nasal Continous Positive Airway Pressure,” American Review of Respiratory Disease, Vol. 140, No. 3, 1989, pp. 717723. http://dx.doi.org/10.1164/ajrccm/140.3.717

[9] M. G. Stewart, D. G. Glaze, E. M. Friedman, E. O. Smith and M. Bautista, "Quality of Life and Sleep Study Findings after Adenotonsillectomy in Children with Obstructive Sleep Apnea,” JAMA Otolaryngology—Head \& Neck Surgery, Vol. 131, No. 4, 2005, pp. 308-314. http://dx.doi.org/10.1001/archotol.131.4.308

[10] F. Larrosa, L. Hernandez, A. Morello, E. Ballester, L. Quinto and J. M. Montserrat, "Laser Assisted Uvulopalatoplasty for Snoring: Does It Meet the Expectations?” European Respiratory Journal, Vol. 24, No. 1, 2004, pp. 66-70.

http://dx.doi.org/10.1183/09031936.04.00082903

[11] H. Buchwald, Y. Avidor, E. Braunwald, M. D. Jensen, W. Pories, K. Fahrbach, et al., "Bariatric Surgery: A Syste- matic Review and Meta-Analysis,” JAMA, Vol. 292, No. 14, 2004, pp. 1724-1737.

http://dx.doi.org/10.1001/jama.292.14.1724

[12] C. W. Zwillich, C. Pickett, F. N. Hanson and J. V. Weil "Disturbed Sleep and Prolonged Apnea during Nasal Obstruction in Normal Men," American Review of Respiratory Disease, Vol. 124, No. 2, 1981, pp. 158-160.

[13] R. C. Heinzer, M. L. Stanchina, A. Malhotra, R. B. Fogel, S. R. Patel, A. S. Jordan, K. Schory and D. P. White, "Lung Volume and Continous Positive Airway Pressure Requirements in Obstructive Sleep Apnea,” American Journal of Respiratory and Critical Care Medicine, Vol. 172, No. 1, 2005, p. 114. http://dx.doi.org/10.1164/rccm.200404-552OC

[14] A. L. Chesson Jr., R. A. Ferber, J. M. Fry, et al., "Practice Parameters for the Indications for Polysomnography and Related Procedures," Sleep, Vol. 20, No. 6, 1997, pp. 406-422.

[15] A. Rechtschaffen and A. Kales, "Manual of Standardized Terminology: Technique and Scoring System for Sleep Stages of Human Subjects," UCLA Brain Information Service/Brain Research Institute, Los Angeles, 1968. 